\title{
Thinking and Willing in Locke's Theory of Human Freedom
}

\author{
RICHARD GLAUSER University of Neuchâtel
}

RÉSUMÉ : Locke a apporté des changements significatifs à plusieurs points de sa psychologie morale au fil des cinq premières éditions de l'Essay. Je ferai valoir qu'en acceptant une certaine liberté de la volonté (willing) dans sa correspondance avec van Limborch (1702) et en concédant une certaine "liberté eu égard à la volonté» dans la cinquième édition de l'Essay (1706), Locke ne compromet pas la cohérence de sa position définitive, contenue dans la cinquième édition, ces libertés étant distinctes du genre de libre arbitre qu'il rejette à maintes reprises. Je tenterai de souligner la continuité de la pensée de Locke sur la liberté humaine en faisant appel à sa théorie de la liberté de penser, qui n'a cessé d'évoluer dès la première édition.

Without Liberty the Understanding would be to no purpose: And without Understanding, Liberty (if it could be) would signify nothing.

Essay, II, $21 \S 67$

The chapter of Locke's An Essay Concerning Human Understanding that deals with the question of freedom (II, 21: "Of Power") is the longest of Book II. It underwent extensive revisions during the Essay's five first editions, ${ }^{1}$ some of which are acknowledged by Locke in II, $21, \$ \S 71-72$, and in the Epistle to the Reader, where he says, "I have found reason somewhat to alter the thoughts I formerly had concerning that, which gives the last determination to the Will in all voluntary action."2 Several changes are due to Locke's recognition and explanation, in the second edition, of weakness of the will, absent in the first edition. His explana- 
tion depends on two issues, duly discussed in the second and subsequent editions: (1) the causal role of the psychological state of uneasiness, and (2) the power to suspend one's desires. All three themes-weakness of the will, uneasiness, suspension of desires-belong to moral psychology. However, we also find another significant modification. Locke repeatedly says that free will is impossible, but in the fifth edition he inserts a passage in which he affirms a certain sort of "Liberty in respect of willing" (\$56).

Three questions arise. Firstly, given that there is some disagreement among commentators as to the nature of Locke's "Liberty in respect of willing," what exactly is it? Secondly, is the belated acceptance of this sort of freedom compatible with Locke's firm and constant rejection of free will? I wish to show that it is: the freedom in respect of willing that he tardily accepts is substantially different from the doctrine of free will that he opposes. Thirdly, given that in $\$ 47$ Locke identifies something as that which his opponents improperly call "free will," we need to find out how that relates to "Liberty in respect of willing." Furthermore, it has been argued that Locke's acceptance of freedom in respect of willing goes hand in hand with a rejection of volitional determinism. ${ }^{3}$ I would like to show that this is not the case; Locke's acceptance of "Liberty in respect of willing" does not bring him to reject volitional determinism. ${ }^{4}$ His change of mind concerning freedom to will is merely another amendment to his moral psychology, and is compatible both with the thesis according to which all volitions are causally determined, and with the thesis according to which free will, as Locke understands it, is impossible. These issues are addressed in Sections 4 and 5.

Sections 1 to 3 cover some preliminary ground related to my main purpose, however, which is to understand the connection between the three changes regarding uneasiness, suspension of desire, and freedom in respect of willing. I wish to show that the three additions, far from being unrelated, are part and parcel of a coherent doctrine. I would also like to show that, although the doctrine emerges gradually from the first edition to the fifth, it highlights the increasing importance of something that was present from the very outset in the first edition: freedom of thinking. Locke gradually comes to realize that he must give freedom of thinking a more prominent role within his moral psychology than he previously had. The three alterations are made for that purpose, so this article attempts to underscore the continuity of Locke's thought on human freedom throughout his changes of mind, the guiding thread being freedom of thinking. This should hardly come as a surprise, given that Locke's very definition of a person comprises not only responsibility and a profound concern for happiness, but also thought, reason, and intelligence. ${ }^{5}$

\section{Volition and Voluntary Action}

The will is an active power, its exercise is a volition. Whereas the will is a disposition, a volition is an actual entity. This seemingly trivial point is 
important to keep in mind in connection with Locke's insistence that faculties or powers, whether passive or active, are not agents. ${ }^{6}$ This implies two things according to Locke. Firstly, it is a category mistake to say that one power has another power. A power is just not the sort of thing that can have a power. Powers necessarily belong to substances, and an active mental power, such as the will, belongs to a substance that is an agent. Secondly, it is a further category mistake to say that a power acts; only an agent can act. And to act is for an agent to exercise one of her active powers.

According to Locke the only effect of a volition is an agent's action: "the will or power of Volition is conversant about nothing, but our own Actions; terminates there; and reaches no farther" $(\$ 30)$. As another quotation shows below, a volition is not directed to just any possible action, but only to a possible action that one believes to be in one's power. There are two kinds of human actions, bodily movements and thoughts. ${ }^{7}$ One's bodily movement or one's thought are voluntary if, and only if, they are directly caused by one's volition to perform them: "The forbearance or performance of that action, consequent to such order or command of the mind, is called Voluntary. And whatsoever action is performed without such a thought of the mind is called Involuntary." 8

What is a volition? Locke makes no attempt to conceal the difficulty he encounters in trying to explain what a volition is; he openly writes with much hesitation in $\S \S 15,28$, and 30 . Yet, the difficulty he encounters is an interesting one; it reveals the complexity of his notion of a volition. On the one hand, a volition is a mental act that can be expressed by verbs such as "commanding," "ordering," "directing," "choosing," or "preferring." Such verbs show that a volition is an operation that necessarily depends in some measure on the perception of ideas, for one can do none of the things expressed by these verbs unless one has an idea of the action that one believes to be in one's power, and that one chooses, prefers, commands, or orders oneself to do. And because what one chooses, orders, etc., is an action that one believes to be conducive-either alone or along with a series of other actions - to the attainment of some good that one desires, then one must also have an idea of the desired good.

On the other hand, although a Lockean volition is distinct from an action as cause from effect, it is intimately connected to an "exerting" of one's power to act, to an attempt or "endeavouring" to act:" "Volition, or Willing, is an act of the Mind directing its thought to the production of any Action, and thereby exerting its power to produce it" ( $\$ 28)$; "Volition is nothing but that particular determination of the mind, whereby, barely by a thought, the mind endeavours to give rise, continuation, or stop to any Action, which it takes to be in its power" $(\$ 30)$. By "intimately connected" I mean that a volition presumably causes the voluntary action in such a way that, if the action needs some time to be accomplished (for example, tying one's shoelaces or typing a page), and as long as there are no imped- 
iments to the performing of the action, the volition accompanies the "exerting" and "endeavouring" from beginning to end, that is to say, until the action is fully accomplished. This is required if the whole action is to be voluntary. The second passage also suggests that a volition pertains only to actions that depend directly on the will, actions that one believes one is able to perform merely by willing to do so ("barely by a thought").

Precisely because a volition typically causes an endeavouring, an exerting of a power to produce an action (that one believes to be in one's power), a volition is very different from a desire. One can desire something without willing, and without trying, to act in order to attain it. Whereas "Desire is directed to the agreeable, ... Will is directed only to our actions and terminates there." 10 Although a volition is always caused by a desire, not every desire causes a volition. Because of this it is possible to have contrary desires and volitions: "I will the Action, that tends one way, whilst my desire tends another, and that the direct contrary" (\$30).

\section{Freedom to Act and Freedom of Thinking}

Locke has a relatively fine-grained account of action. His many examples show that he distinguishes between: beginning to do $\mathrm{A}$ (or just doing $\mathrm{A}$ ); refraining from beginning to do $A$ (or just refraining from doing $A$ ); continuing to do $\mathrm{A}$ (when $\mathrm{A}$ is a kind of action that can be continued) in circumstances where one might hesitate as whether to continue or not; and ceasing to do A. All of these are ways of acting, and can be done either voluntarily or involuntarily. ${ }^{11}$ To make matters simpler for the purposes of this article, however, let us distinguish merely between doing $A$ and doing B, where A and B are incompatible or "contrary" actions in the sense that they cannot be performed simultaneously, although, given proper circumstances, one could be done instead of the other. For example, if $A$ is to stay in a room, B could be to leave the room; if $A$ is to smoke a cigarette, $B$ could be to refrain from doing so, etc.

Chappell is right to say that Locke is basically a compatibilist, holding that all actions, free or not, are causally determined. ${ }^{12}$ What might seem to make him sound like an incompatibilist, when compared with Hobbes and Hume, is that he uses "free" and "necessary" as contradictory terms. But that is only a verbal matter, for in II, 21 "necessary" means "nonfree," not "causally determined." Now, according to Locke, an agent acts freely in doing some action A if, and only if: (1) A is done voluntarily; (2) the agent could act otherwise instead and do some contrary action B (where $\mathrm{B}$ might be no more than refraining from doing $\mathrm{A}$ ). The latter clause means that it is entirely up to the agent to do B instead of $\mathrm{A}$ if she so wills. ${ }^{13}$ When condition (2) is satisfied, we have what Locke calls "Indifferency of Ability on either side to act" $(\S 10)$, "an indifferency of the operative Powers of the Man" (\$71). He defines this indifferency negatively as the absence of both restraint and compulsion, which are two forms of 
what he calls "necessity," i.e., the absence of freedom. ${ }^{14}$ One does A freely, then, when one wills to do $A$ in circumstances in which there is no internal or external restraint preventing one either from doing $A$ or from refraining from doing $A$, and no internal or external compulsion forcing one either to do A or to refrain from doing A. ${ }^{15}$ It is important to notice, too, that restraint and compulsion can be either (1) inner, psychological forces, (2) bodily states (such as palsy or a convulsion ${ }^{16}$ ), or (3) external factors. Thus, indifferency, as understood by Locke, is not a psychological state. When indifferency relates to bodily action it includes a certain state of the agent's body and a certain state of her surroundings at the time of acting. As we shall see, the sort of indifferency essential to freedom of bodily action and of thought must be distinguished from the "antecedent indifferency before the decree of the Will," which Locke rejects, but which his opponents take to be necessary to free will. ${ }^{17}$ Another point to be kept in mind is that the indifferency essential to freedom to act is jeopardized only by restraint and/or compulsion, not by causal determinism. That is to say, an action can be performed freely and yet be causally determined. Indeed, an action performed freely is voluntary by definition, and so is always causally determined by a volition. In sum, voluntariness is not a sufficient condition of an action's being performed freely; it is only a necessary condition. We have three kinds of actions: involuntary (not free, i.e., necessary), voluntary but not free (necessary), and voluntary and free.

Most of the examples of free action discussed by Locke in II, 21 are bodily movements. It is important to keep in mind, though, that some modes of thinking are voluntary actions, too. When Locke first makes the distinction between voluntary and involuntary actions in II, 21, he applies it to thought: "This Power which the mind has, thus to order the consideration of any Idea, or the forbearing to consider it . . . is that which we call the Will" ( $\$ 5)$. Furthermore, in some cases thinking can be performed freely: "so far as a Man has a power to think, or not to think . .., according to the preference or direction of his own mind, so far is a Man Free. Where-ever any performance or forbearance are not equally in a Man's power ... , [and] will not equally follow upon the preference of his mind directing it, there he is not Free, though perhaps the Action may be voluntary" (\$8). Locke is here explaining freedom of thinking in terms of an "Indifferency of Ability on either side to act."

In II, 19 Locke gives a list, that he himself considers incomplete, of what he calls "modes of thinking." Because he includes volitions among these modes (cf. II, 19, §2), it would be mistaken to oppose volitions to modes of thinking. However, one can distinguish volitions from a subclass of modes of thinking. I wish to contrast, within the class of modes of thinking (an expression I hereafter drop), (1) volitions with (2) deliberation and a variety of acts of thinking which, under certain conditions, can all be included in a process of deliberation: acts such as thinking of a 
certain idea rather than another, examining an idea attentively, comparing ideas, judging, reasoning, giving one's assent, and so on. Such acts of thinking are those that we find in Locke's theory of freedom of thinking.

Just as freedom to perform bodily actions is limited, so is freedom of thinking. For instance, Locke explains to his Dutch Remonstrant friend Philippus van Limborch that if the expression "act of the understanding" means "that action by which one perceives that something is true," then such an act cannot be performed freely. If a man perceives that the sum of the three angles of a triangle are equal to that of two right angles, he "is not free because when the demonstration has been examined he is unable not to understand this." ${ }^{18}$ Another limitation: while awake, an agent is "under the necessity of having some Ideas constantly in his Mind, [and] is not at liberty to think, or not to think" $(\$ 12)$. Yet, the agent is often free to think of some ideas rather than others. For, if "act of the understanding" means "an action of thinking about some subject," then "a man is for the most part free in actions of the understanding of that sort: for example: I can think about Adam's sin, or remove my cogitation thence to the city of Rome or to the art of war in the present age. In all these actions I am free because I am able at my pleasure to think about this or that." ${ }^{19}$ Such freedom is itself limited and can be momentarily impaired by restraint or by compulsion, as when a man on the rack "is not at liberty to lay by the Idea of pain, and divert himself with other Contemplations," or when a violent passion "hurries our Thoughts" and prevents one from considering certain ideas that one would gladly consider in other circumstances $(\$ 12)$. When an agent's freedom is not thus impaired, however, he is sometimes free to consider certain ideas attentively or not: "he may commonly chuse, whether he will heedfully observe and consider them [his ideas]."20

In sum, freedom of thinking is on a par with freedom of bodily action. They are structurally identical in all essentials. Both are explained by voluntariness, and by "Indifferency of Ability on either side to act"; both are empirically limited. If freedom of bodily action is compatible with causal determinism, as Locke holds, then so is freedom of thinking.

In $\$ \S 5-12$, freedom of thinking and freedom of bodily action are discussed as if they were two parallel, unconnected domains of freedom, with the agent pictured as controlling by will (in some measure) acts of thinking on the inside, and bodily actions on the outside. Of course, this provisional picture is an oversimplification, because voluntary bodily action depends on thought. A volition is always a volition to do some action that the agent considers within her power, so it depends on an idea of that action and on an idea of the agent's power; because a volition is caused by a desire, it also depends, indirectly, on the idea of some desired good.

More will be said about volition and thinking in the next sections. Let us mention here that each and every volition also depends on what Locke calls a "last judgement" of the understanding. ${ }^{21}$ What is a judgement? It 
is an act of the understanding, but not an act of perceiving the agreement or disagreement of ideas. It is an act "whereby the Mind takes its Ideas to agree, or disagree; or which is the same, any Proposition to be true, or false, without perceiving a demonstrative Evidence in the Proofs"; it is an act where "Agreement or Disagreement is not perceived, but presumed" (IV, 14, $\$ 3$ and 4). Judgements are made, typically, with regard to complex, contingent matters, where, instead of certain knowledge, we have only probability. In some cases judgements are voluntary: "Assent, Suspense, or Dissent, are often voluntary Actions" (IV, 20, §15). Sometimes, too, one is free to assent or to withhold assent as one wills. This is the case in two sorts of situations. It is the case, firstly, when one wishes to take a stand on an issue involving two alternative possible courses of action where the probability is perceived to be approximately equal on both sides. (However, as soon as the probability is perceived to be significantly greater on one side than the other, it is not within one's power to refrain from assenting. ${ }^{22}$ ) This sort of "freedom" to assent or to withhold assent is not a positive power; it is a sign and consequence of ignorance. Secondly, one can withhold assent merely by breaking off one's present enquiry and directing one's thoughts elsewhere: "we can hinder both Knowledge and Assent, by stopping our Enquiry, and not imploying our Faculties in the search of any Truth" (IV, 20, §16). If one is free to pursue or to refrain from pursuing an "enquiry," then one is surely also sometimes free to begin to deliberate or to refrain from doing so. This suggests that deliberation can sometimes be performed freely.

What is a "last" judgement? It is a judgement that immediately precedes and determines a volition. Locke says that it is "about the thing to be done," ${ }^{23}$ that is to say, about an action proposed to the understanding and presumed to be within one's power. But it is not "about" an action in the same sense in which a volition is. A volition is "about" an action in that it is always a volition to do (or to refrain from doing) something. A "last judgement," on the other hand, is an evaluative judgement having the general form: "this [is] better for here and now." One might say that it is "about" an action in that it has as its object a proposition about the action, one of the form "this [is] better for here and now." ${ }^{24}$ One should not confuse a last judgement with a desire. A desire is always aimed at a good thing, whereas a last judgement is "about" (in the sense mentioned above) an action presumed to lie within one's power, and proposed to the understanding as a step towards attaining that good. However, as Locke makes clear to van Limborch, a last judgement is not necessarily a "mature and right judgement"; it does not necessarily result from deliberation, for "that judgement ... which is in reality the last judgement" is so "whether it has been well pondered and recast by mature deliberation, or is extemporaneous and sprung from a sudden impulse; and equally determines the will, whether or not it is in accordance with reason." This is why "every 
single volition is always preceded by some judgement of the understanding about the thing to be done." 25 Thus, one should not construe the exercise of the understanding as merely that of making judgements on very general issues, such as whether this or that sort of good should be pursued. The exercise of the understanding, whether rashly or carefully conducted, also determines which specific action is to be performed hic et nunc.

What is important for the purposes of this paper is that a last judgement is sometimes the result of deliberation, and that, because deliberation is an exercise of thought, in some cases at least deliberation can be performed freely. This means that in some cases, morally significant or not, the agent acts according to the last judgement of her deliberation in such a way that both her deliberation and her bodily action are performed freely. In such situations, we have freedom to act (bodily movement), we have freedom to think and deliberate; yet, according to Locke, we do not have free will. And one may well wonder why not. I must postpone discussing Locke's reasons for rejecting free will until Section 5. More must be said, before that, about Locke's moral psychology and about freedom of thinking (Sections 3 and 4).

\section{Uneasiness and Freedom of Thinking}

Free actions are causally determined by volitions. What are volitions caused by? In the first edition of the Essay Locke held that they are directly determined by ideas of a certain good: "'tis as much a perfection, that the power of Preferring [the will] should be determined by Good, as that the power of Acting should be determined by the Will; and the certainer such determination is, the greater the perfection." ${ }^{26}$ One of the theoretical modifications made in the second edition is that what immediately determines a volition is no longer the idea of a certain good, but a conative, motivational state, an uneasiness closely connected to a desire for some absent good represented by an idea. So, in the second edition, Locke says: "Good and Evil, present and absent, 'tis true, work upon the mind: But that which immediately determines the Will, from time to time, to every voluntary Action, is the uneasiness of desire, fixed on some absent good." 27 Thus, the uneasiness of desire is fitted into the psychological causal chain as an intermediate link between the idea of a good and the volition. Determinism is unaffected by the change; the causal chain merely acquires an intermediate link. ${ }^{28}$

What moved Locke to change his mind? In the first edition he took it for granted-as "a maxim" received "by the general consent of all Mankind"-that "the greater good, determines the will" (\$35). In the second edition he corrects this view: "I am forced to conclude, that good, the greater good, though apprehended and acknowledged to be so, does not determine the will, until our desire, raised proportionably to it, makes us uneasy in the want of it" (\$35). According to Locke, the theory of uneas- 
iness is justified both by "Experience" and by "the reason of the thing" (\$33). Weakness of the will is one of the facts of experience, according to Locke, that can be explained only if we grant that it is some uneasiness, not the idea of a certain good, that directly motivates one to will. Let us focus on just two points in Locke's explanation of weakness of the will. ${ }^{29}$ Firstly, it often happens that some ideas of absent great goods produce no uneasiness, and so have no effect on the will. ${ }^{30}$ Secondly, even when we consider ideas of absent goods that all happen to produce their respective uneasinesses, there is frequently some disproportion between the comparative greatness or smallness of the represented goods and the comparative strength or weakness of their corresponding uneasinesses. ${ }^{31}$ That is to say, an idea of an absent good, believed by the agent to be a much lesser good than another absent good represented by another idea, may yet produce a much stronger uneasiness than the one caused by the idea of the good believed to be greater. In both cases the agent acknowledges a good to be greater than others: "'Tis not for want of viewing the greater good: for he sees, and acknowledges it" (\$35). Yet, either he is unmotivated to pursue the greater good (its idea produces no uneasiness), or he is insufficiently motivated to do so (its idea produces a weaker uneasiness than does an idea of an acknowledged lesser good). Of course, Locke does not believe that his theory of uneasiness is required merely to explain weakness of the will; he uses it to explain human action in general. ${ }^{32}$ Accordingly, the general theory of uneasiness depends on two claims that hold for the explanation of ordinary action as well as for cases of weakness of the will: (1) two uneasinesses cannot simultaneously cause two volitions, for we are "capable but of one determination of the will to one action at once" ( $\$ 36)$; (2) whenever an agent has different uneasinesses at the same time, the one that "has the precedency in determining the will" is "that ordinarily, which is the most pressing of those, that are judged capable of being then removed" ( $\$ 40$, my italics).

Before addressing the issue of suspension of desire, let us see how Locke's theory of uneasiness relates to the power of thought. On the one hand, an agent's mere thinking of good things has no immediate effect on her willing, because the mere having ideas of absent goods, however great, is not sufficient by itself to motivate one to will to act towards attaining these goods. On the other hand, though, an agent's thinking of goods has a mediate effect on her willing, because some ideas of absent goods nevertheless do produce uneasinesses that successively determine the will. The ideas that do so are ideas of absent goods that the agent believes conducive to the (partial) satisfaction of her general desire for happiness. But there is much more to the relation between thinking and willing, for the question obviously arises as to how an agent, when possible, can bring it about that an idea of a great absent good either (1) produces some uneasiness if it has not yet done so, or (2) strengthens an uneasiness if the uneas- 
iness it has produced is considered disproportionately weak, or weakens one that is considered disproportionately strong. And in case the agent realizes that she suffers from weakness of the will, the question arises more generally as to how she can work towards bringing it about, when possible, that her various, competing uneasinesses, according to their respective strength or weakness, more appropriately fit the greatness or smallness of the absent goods that she believes conducive to the (partial) satisfaction of her general desire for happiness. For instance, how does one see to it that a weaker desire is "raised proportionably" to the idea of a greater good so that it "makes us uneasy in the want of it"? Nothing less than such a power is required if agents are to be rational moral persons working to attain their true happiness.

What is needed is "due and repeated Contemplation" of the idea of a certain great, absent good, so as to bring "it nearer to our Mind," to give us "some relish of it," to raise "in us some desire; which then beginning to make a part of our present uneasiness, stands upon fair terms with the rest, to be satisfied" ( $(45)$. "And thus, by a due consideration and examining any good proposed, it is in our power, to raise our desires, in a due proportion to the value of that good, whereby in its turn, and place, it may come to work upon the will, and be pursued" (\$46). Hence, we have "a power to raise our desires," and that power is the understanding, the power of thinking: it consists in the careful, attentive consideration and examination of ideas of absent goods. And this power cannot be restricted to the mere perception of such ideas taken individually. It must also extend to the comparison of several ideas of goods, so as to focus on the "Connexion or Repugnancy, Agreement or Disagreement, that there is between . . . our Ideas." Or, if we lack certain knowledge and must rely on probable judgement, we must at least be able to presume agreement or disagreement between certain ideas. Indeed, one must be able to compare the various ideas of the proposed absent goods one with another, and with the idea of our happiness, in order to judge which of the goods should, or should not, be pursued according to the circumstances. Now, the exercises of the understanding are sometimes voluntary, "the will having a power over, and directing the thoughts, as well as other actions" (\$38). And, as we have seen, to a certain extent this power can be exercised freely. Indeed, it has to be exercised freely in some cases, for the whole point of deliberation is that, when one is confronted with various ideas of absent goods and one has the intention of trying to bring about some change in the respective strength or weakness of one's uneasinesses towards them, one's understanding must be in a state of "Indifferency of Ability on either side to act." That is to say, it must be possible for the agent to attentively consider at will, or to refrain from doing so at will, now the idea of this absent good, now the idea of that, now the idea of that other, and, if still in doubt, to reconsider any of the previous ideas, etc., so as to repeatedly 
examine and compare them for so long as it takes to reach a last judgement that determines exactly what specific action should be undertaken hic et nunc. This is freedom of thinking during deliberation.

Thus, Locke's first important addition to the second and subsequent editions of the Essay-his theory of uneasiness-is closely connected to his theory of freedom of thinking already present in the first edition. The theory of uneasiness is not merely that it is always some uneasiness that immediately determines a volition, motivates one to will. It is also that uneasinesses can in some limited measure be produced, strengthened, or weakened by the voluntary and free exercise of the understanding in deliberation.

At this point, it should be said that Locke's position in the previously quoted letter to van Limborch may seem to be somewhat at odds with the main line that Locke takes in Essay II, 21 as to what immediately determines the will. According to II, 21, what immediately determines the will is an uneasiness. Yet, Locke explains to van Limborch (in 1701) that a last judgement always "immediately precedes volition," and that it "determines the will." 33 This means that it immediately determines the will. There is no reason to believe that Locke is contradicting himself, however. All that needs to be done, since he suggests as much, is to assume that both together immediately determine the will, but in two different senses of "determine." The assumption comes down to this: on the one side, an uneasiness connected to a desire of an absent good immediately determines a volition in the sense that the uneasiness directly motivates one to will (to perform some action in order to attain the desired good). On the other side, a last judgement immediately determines a volition in the sense that it directly determines which sort of action one is to will in order to pursue the desired good hic et nunc. The two factors are inseparable: without an uneasiness, one would not be motivated to will; without a last judgement, whether rash or well considered, one would not know what sort of action to will. Both together cause the volition.

In sum, the power of the understanding to determine a volition is both mediate and immediate, in two different respects. The exercise of the understanding in deliberation can only mediately motivate a volition; this is done by producing or heightening an uneasiness connected to a desire of some absent good. The exercise of the understanding, by way of a last judgement (whether the result of deliberation or not), immediately determines a volition by fixing the sort of action to be willed hic et nunc.

\section{The Suspension of Desire and What Is Improperly Called Free Will}

The theory of suspension of desire is the second important addition Locke makes to the second edition. The connection between this theory and that of uneasiness is straightforward, provided one has in mind the central role of the understanding and its free operation. Suppose one simultaneously has several uneasinesses caused by ideas of different absent goods, and 
that one wishes to attentively examine these ideas and to deliberate before acting. If one of the more powerful uneasinesses determined one to will to act before the process of deliberation were completed, the whole point of the process would be defeated since one would not be acting according to the result of one's deliberation. Therefore, as long as the process of deliberation is going on the agent must have some power to momentarily prevent her present uneasinesses from causing a volition to act. Such a power, of course, is limited; some uneasinesses may be overwhelming, but without it the very attempt to examine one's ideas of absent goods and to deliberate would be pointless. This is why Locke repeats that it is not inevitably the case that the most powerful uneasiness that one has at a certain moment determines the will; it does so only "ordinarily," "for the most part," that is, when one does not suspend one's desires in order to deliberate, whatever the reason for not deliberating may be. ${ }^{34}$

[I]t is natural ... that the greatest, and most pressing [uneasiness] should determine the will to the next action; and so it does for the most part, but not always. For the mind having in most cases, as is evident in Experience, a power to suspend the execution and satisfaction of any of its desires, and so all, one after another, is at liberty to consider the objects of them; examine them on all sides, and weigh them with others. In this lies the liberty Man has; and from not using it right ... we precipitate the determination of our wills, and engage too soon before due Examination. To prevent this we have a power to suspend the prosecution of this or that desire, as every one daily may Experiment in himself. This seems to me the source of all liberty; in this seems to consist that, which is (as I think improperly) call'd Free will. (\$47)

Clearly, Locke refuses to call the kind of freedom discussed here "free will," although he acknowledges that others improperly call it so. And one can well understand why he refuses. For what the power to suspend one's desires enables is the effective use of one's power to freely deliberate. Locke's point is that it is freedom to think, not freedom to will, that is enabled by the suspension of desire. Also, a close reading of the passage will detect a subtle distinction between, on the one hand, what liberty "lies in," i.e., consists in, and, on the other hand, "the source of all liberty." What the liberty under consideration "lies in" is freedom to deliberate, the "liberty to consider the objects of them; examine them on all sides, and weigh them with others." However, the "source" of liberty is the power of suspension. And Locke says that it is the power of suspension that is improperly called "free will" by others: "the source of all liberty; in this seems to consist that, which is (as I think improperly) call'd Free will." 35

Why is the power of suspension, according to Locke, the "source" of liberty? Because, in optimal circumstances, suspension is what enables deliberation to be carried out until a careful last judgement determines one to 
will to act. But the "source" of the free exercise of the power of thought and deliberation is not identical to the free exercise itself. In another passage, Locke calls the power of suspension "the hinge on which turns the liberty of intellectual Beings in their constant endeavours after ... true felicity" (§52). But again, one cannot just identify "the hinge" with the liberty that "turns" on it. And the fact that the liberty in question is that of "intellectual Beings" clearly suggests that the liberty under discussion is that of thought in deliberation, which is distinct from the power of suspension.

However, in another passage Locke combines the two together, saying: "The first therefore and great use of Liberty, is to hinder blind Precipitancy; the principal exercise of Freedom is to stand still, open the eyes, look about, and take a view of the consequence of what we are going to do, as much as the weight of the matter requires" (\$67). It is slightly inaccurate to say, as Ayers does, that in this passage Locke suggests that the power of suspension "really constitutes the liberty of rational agents." 36 True, "to stand still" is to suspend one's desires, as Locke explains elsewhere. ${ }^{37}$ But "to open the eyes, look about, and take a view of the consequence of what we are going to do" is an exercise of the power of thinking. In this passage "the principal exercise of freedom" includes both suspension and deliberative thinking. The same appears in $\S 52$, where suspension is called both the "inlet" and the "exercise" of liberty. ${ }^{38}$

In sum, Locke wavers between two positions. Sometimes, suspension of desire is presented as no more than an important necessary condition of freedom to think in deliberation; it is a "source," a "hinge," an "inlet," on which the latter depends, but is distinct from the latter. At other times, as in $\S 67$, it is assimilated to freedom of deliberation, presumably for the following reasons: (1) it is such an important necessary condition that it can be considered a part of a whole continuous process, the other part of the process being deliberation; the entire process, comprising both suspension and deliberation, is condensed in the phrase "to stand still, open the eyes, look about, and take a view of the consequence of what we are going to do"; (2) the act of suspending one's desires and the process of deliberation are performed for exactly the same reason in the long run; both aim at the same goal; (3) the duration of suspension is roughly the same as that of deliberation. (A fourth reason will be provided below.) Although these reasons suffice to explain why Locke sometimes brings together the power of suspension and the power to deliberate, this should not obscure the fact that, strictly speaking, the momentary suspension of one's desires is no more than a necessary condition of the exercise of one's freedom to deliberate.

At this point two questions arise: (1) Is the act of suspension ever voluntary? (2) Can it sometimes be performed freely? It must be possible for us to suspend our desires freely in some cases at least, for Locke considers deliberation to be a moral obligation, a duty. ${ }^{39}$ And if it can be done freely in some cases, it can be done voluntarily. Remember that "Assent, Sus- 
pense, or Dissent, are often voluntary Actions." Therefore, as to the first question, Locke would be willing to grant that suspension is sometimes caused by a volition, itself caused by an uneasiness, presumably the kind of uneasiness caused by conscious doubt as when "we are not sufficiently assured of the way" ( $\$ 50)$. Ayers sees a problem here, asking: "If reason cannot directly move to action, how can it directly move to deliberation?" ${ }^{40}$ But if the reading proposed so far is correct, there is no reason to believe that reason directly moves to deliberation. The relation between reason and deliberation is only indirect. Presumably, a certain epistemic state of "reason," i.e., doubt-along with the idea of an absent good (such as acting in a more enlightened way)-produces an uneasiness, and this is what directly motivates one to will to suspend one's desires and to deliberate.

If Locke accepts freedom to suspend one's desires, as I have suggested, all that is required is that he grant two rather uncontroversial points. First, we are to count among actions not only bodily movements and acts of thinking, but also acts of suspending desire. And, secondly, in some circumstances it is within one's power either to voluntarily suspend one's desires or to refrain from doing so, without restraint nor compulsion. If this interpretation is correct, we are still dealing with the same old model of freedom to act as one wills: the "Indifferency of Ability on either side to act." The only thing that the suggested reading requires is that we extend this indifferency, with due empirical limitations, to the power to suspend one's desires. In doing so, we do not depart from Locke's basic conception of freedom to act. If one accepts this reading, one has a further (fourth) reason for which Locke tends at times to assimilate suspension with deliberation: in certain circumstances both can be exercised freely. Finally, if, as this reading suggests, freely suspending one's desires is similar - in the ways mentioned - to freely producing a bodily movement as one wills, and to freely thinking of this or that idea as one wills, then it, too, is compatible with causal determinism.

We have seen that, according to Locke ( $\$ 47)$, what some of his opponents improperly call "free will" is no more than the free exercise of the power of suspension in order to deliberate. And it should now be clear why this is not free will: freedom to suspend one's desires is freedom to act in a certain way as one wills, not freedom to will. This is why it is important not to confuse freedom to suspend one's desires, with a purported freedom to will to suspend one's desires. I now turn to Locke's rejection of free will, and to his eventual acceptance, in the fifth edition, of a certain sort of freedom in respect of willing. (This will not be freedom to will to suspend one's desires.) The next section addresses whether Locke's tardy acceptance of a freedom in respect of willing is consistent with his denial of free will, and how both issues bear on what is "improperly called free will," the power to freely suspend one's desires. 


\section{Freedom in Respect of Willing vs. Free Will}

Locke has three arguments (in $\S \S 14-17,23-24$, and 25) purporting to show that free will is impossible. Because Chappell has well analyzed them, I hereafter refer the reader to Chappell's reconstructions. ${ }^{41}$ I shall only briefly summarize the main points of each argument. However, Chappell also critically assesses the relation of the arguments to Locke's evolving, global position in II, 21, and I disagree with some of his interpretations, so I shall take a stand on a few of Chappell's objections, in the hope of gradually sketching out a picture of Locke's position on freedom in respect of willing that is perhaps more consistent than may otherwise appear. At the end of this section, I return to the issue of freedom to suspend one's desires, improperly called "free will."

The first reason for which Locke denies freedom of the will is that the will is one active power, freedom is another active power, and one power cannot belong to another. Powers necessarily belong to agents and to agents alone. Thus, it is a category mistake to say that the will is free.

The point is well taken. But a friend of free will could rephrase her position so as to avoid the category mistake. One could say, for instance, that just as an agent is sometimes free to act (with respect to bodily movement, to suspension, or to thinking), she is also sometimes free to will. Locke foresees the objection and proceeds to block it with a second argument, purporting to show that " $a$ Man in respect of willing, or the Act of Volition, when any Action in his power is once proposed to his Thoughts, as presently to be done, cannot be free" (\$23). The conclusion is that in any circumstances where one considers an action "as presently to be done," it is necessarily the case either that one wills the action to be done or that one wills it not to be done. Chappell calls this the "unavoidability thesis" and points out, correctly, that it "ascribes necessity de dicto to a proposition about agents. . . . It says that if an agent thinks about doing something $x$, then it is necessary that either he will to do $x$ or else he will not to do $x$." This must be distinguished from the thesis of volitional determinism, which "applies to concrete acts of willing, and ... ascribes necessity de re to all of them." The two theses are logically distinct. ${ }^{42}$ The volitional determinism thesis is not part of the argument of $\$ 23$, whereas the unavoidability thesis is. In a nutshell, when an agent considers an action "as presently to be done," she is not free to will or not to will because it is necessarily the case either that she wills the action to be done or that she wills it not to be done. In either case, she wills.

Let us make two remarks about this argument. First, Chappell says, following Leibniz, that the unavoidability thesis rests on a false premise: "if the man considering such an action did not will it not to exist, it would not not exist." The premise seems wrong to Chappell because he thinks that it is contradicted by the fact that one can suspend one's desires in order to deliberate; in such a case, during deliberation, one does not perform the 
action under consideration, yet this is not because one wills it not to exist. Still worse, according to Chappell the erroneous premise makes Locke's position contradictory, because he himself claims that we have the power to suspend our desires. ${ }^{43}$ However, Chappell's reading seems to me to be excessively uncharitable. Why? Locke explicitly restricts the scope of his argument to cases where the action under consideration is "once proposed to his Thoughts, as presently to be done," i.e., right away. Locke is surely using "once" not to mean "as soon as," but as shorthand for "as soon as and so long as." For instance, we often say things such as: "Once the ship is under way we shall arrive at Cobh in four hours." In such a context "once" is taken to mean "as soon as and so long as," for it goes without saying that we shall not arrive at Cobh in four hours as soon as the ship is under way, if the engines happen to break down en route. What Locke surely means is that as soon as and so long as an action is proposed to one's thought as presently to be done, i.e., right away, if one considering such an action did not will it not to exist, it would not not exist. Notice that it is not obvious that this claim is mistaken; if it is, it is not for the reason given by Chappell, for consider the following alternative: either suspension of desire is done voluntarily or it is done involuntarily. If it is done voluntarily, Locke could reply to Chappell that by suspending his desires in order to deliberate, the agent postpones both willing the action to exist and willing it not to exist. In which case, because the action appears to the agent as one that can be postponed until the process of deliberation is completed, the action is not "proposed to his Thoughts, as presently to be done," i.e., right away. If, on the contrary, the suspension of desire is involuntary, perhaps when one's attention is suddenly diverted and captivated by intruding ideas, then the "so long as" clause is not respected. If the agent is suddenly distracted by intruding thoughts, it is no longer the case that the action initially considered remains "proposed to his thoughts." 44

Second, even if Locke can be defended in the way suggested, this does nothing to remove another apparent difficulty. The unavoidability thesis is taken by Locke, in $\S 23$, to apply specifically to acts of the will. But notice that, at first glance, nothing seems to prevent it from applying to free bodily actions as well. To elaborate on one of Locke's examples, suppose a person in a room with an open door freely remains there. Her remaining in the room freely is due to the "Indifferency of Ability on either side to act": she could go out if she so willed. Yet, it seems that the unavoidability thesis applies to her situation, for it seems necessary that either the person remain in the room or that she leave it. In other words, the unavoidability thesis thus applied seems compatible with the indifferency essential to freedom of action. If so, why is it supposed to rule out freedom to will?

Presumably, Locke's reply to the objection would go along the following lines. Both willing an action to exist and willing an action not to exist are ways, or modes, of willing, just as leaving a room or staying in it are ways, 
or modes, of situating one's body in relation to a room: inside of it or outside of it. Just as one is not free (once and so long as one considers an action as presently to be done) to refrain from some act of willing (either one wills the action to exist or one wills it not to exist), just so, if one is in a room, one is not free to refrain from situating one's body in relation to the room (either one remains in it or one leaves it). Thus, the necessity of willing captured by the unavoidability thesis is similar to the necessity of thinking, and to the necessity of having one's body touch another. While awake, a person "is not at liberty to think, or not to think; no more than he is at liberty, whether his Body shall touch any other or no"-for a "waking Man" is "under the necessity of having some Ideas constantly in his Mind," and, awake or not, of having his body touch at least some other physical object $(\$ 12)$. Similarly, so long as an action is proposed to one's thoughts as presently to be done, one is not at liberty to will or not to will.

But this reply will prompt two rejoinders from Locke's adversaries. The first is this. The argument based on the unavoidability thesis, as the argument is phrased, attains its conclusion only if restricted to situations where suspension of desire does not enter the picture. The conclusion is not universal in scope, applying only to a certain class of actions, so how does the unavoidability thesis fare once suspension of desire is taken into account? Let us postpone an answer to this question for a bit. The second rejoinder is this. The real question concerning free will is independent of the unavoidability thesis insofar as an advocate of free will could grant the unavoidability thesis, and yet assert that an agent is free, in certain circumstances, either to will a certain action to exist or to will it not to exist. Just as, according to Locke himself, one is free in certain circumstances to think of this idea rather than that (although one is not free to think or not to think), and just as one is free in certain circumstances to have one's body touch this physical object rather than that (although one is not free to have one's body touch something or not), just so it seems that one should be free, in certain circumstances, to will an action to exist or to will the action not to exist (although one is not free to will or not to will).

Let us begin with the second question. Locke seems to have foreseen it, for he tries to answer it in his third argument against freedom to will (\$25). The conclusion to be reached is a negative reply to the question, "Whether a Man be at liberty to will which of the two he pleases, Motion or Rest." The argument is by all standards extremely elliptical, and all the more difficult to interpret in detail. Again, we follow Chappell's reconstruction. ${ }^{45}$ Locke believes that if it were possible to be free to will an action to exist or to will it not to exist, i.e., to will some contrary action to exist instead, then one would be involved in an infinite regress: one would have to "suppose one Will to determine the Acts of another, and another to determinate that; and so on in infinitum" (\$25). It seems that Locke is relying here on the thesis according to which a free action is voluntary by definition; 


\section{Dialogue}

i.e., it is caused by a volition, so that, if one willed motion freely (i.e., in circumstances in which one could also will rest), the volition to move would itself have to be caused by an antecedent volition. But this is not all, for the second volition could only belong to another will ("one Will to determine the Acts of another"). Not only would there be two volitions, but each volition would belong to a different will, as if an agent could have more than one power of willing! This is why one should accept as an implicit premise what Chappell calls the "heteronomy principle": "no will determines itself, i.e., determines the acts of willing which belongs to it." But why should there be an infinite regress? Why not just stop at a second volition, belonging to a second will? Because of another implicit premise, which Chappell calls "the inheritance principle": "an agent is free with respect to an act, only if he also is free with respect to the act of willing which produces that act." This is what brings it about that the second volition should itself be caused by a third, and so on, with as many different wills at each stage. Obviously, Locke does not accept the inheritance principle, since he holds that free actions, such as some bodily movements and thoughts, are causally determined by volitions that are not exercised freely. This is why the argument of $\$ 25$ must be construed as ad hominem; it is not Locke, but his opponents, who hold the inheritance principle.

However, Chappell considers it extremely unlikely that it is an ad hominem argument, because Locke's opponents would not have accepted the heteronomy principle, to which Locke is committed ${ }^{46}$ But this objection to an ad hominem construal of the argument of $\$ 25$ seems unconvincing. Locke may have any number of reasons for believing that his opponents just do not have the right to deny the heteronomy principle. Which reasons? No one can be sure. But here is a suggestion. If a will had the power to determine itself, one of its exercises would be a volition to produce a volition. And Locke may well consider this psychologically impossible. For it is not at all obvious what a volition to produce a volition could be, given that a volition immediately causes and accompanies an "exerting," an "endeavouring," or trying to do something. For instance, what could it be to will to will to tie one's shoelaces, to take a bath, or even to stop smoking? Of course, second-order desires are perfectly in order, as are desires to will; and so are evaluative approvals of one's volition. One can desire to desire a certain good; one can desire to will and to endeavour to do something; and one can approve of one's volition to do something. But we have seen that desire and volition are quite distinct in Locke. Keeping this in mind, it is just not obvious that there are any willings to will to do something; there may only be first-order volitions to act. ${ }^{47}$ If so, then, although a volition is an act of the mind, and although one may wholeheartedly approve of one's present volition, a volition is just not the sort of act that can be performed voluntarily, at least if an act is voluntary if, and only if, it is directly caused by one's volition to perform it. A second reason for believing that Locke 
would deny the existence of volitions to will is that he holds, we have seen, that every volition is immediately caused by an uneasiness and a last judgement. If so, then no volition can be immediately caused by a prior volition, that is to say, there are no willings to will and one cannot will as one wills. Thus, we have a quite plausible reason for which Locke would deny his opponents the right to reject the heteronomy principle. Indeed, there is further reason to attribute this view to Locke, because it is a good interpretation of what he is getting at in $\$ 25$ when he says with scathing irony: "to ask, whether a Man be at liberty to will either Motion, or Rest ...; which he pleases, is to ask, whether a Man can will, what he wills; or be pleased with what he is pleased with. A Question, which, I think, needs no answer," the answer being obviously negative. ${ }^{48}$ Locke's point here seems to be that volitions are always necessary (non-free) because they cannot be performed voluntarily (at least in the sense mentioned above). Therefore, pace Chappell, the argument of $\$ 25$ can, and should, be taken as ad hominem.

A significant feature of the three arguments against free will is that none of them purport to show that volitions are not free merely because they are causally determined. Indeed, if that were a sufficient reason to reject freedom to will, the same reason would cancel freedom of bodily action, freedom of thinking, and freedom of suspension. The fact that Locke does not argue that free will is impossible merely because volitions are causally determined highlights his compatibilism.

Let us return now to a question mentioned above. The argument based on the unavoidability thesis (\$23), as the argument is phrased, attains its conclusion only if restricted to situations where one does not suspend one's desires. So how does the unavoidability thesis fare once suspension of desire occurs? Locke adds a passage in the fifth edition to the effect that, in cases where one does suspend one's desires, the unavoidability thesis does not apply. And because it does not apply to such cases, Locke concedes that there is, after all, some sort of "liberty in respect of willing."

[I]n most cases a Man is not at Liberty to forbear the act of volition; he must exert an act of his will, whereby the action proposed, is made to exist, or not to exist. But yet there is a case wherein a Man is at Liberty in respect of willing, and that is the chusing of a remote Good as an end to be pursued. Here a Man may suspend the act of his choice from being determined for or against the thing proposed, till he has examined, whether it be really of a nature in it self and consequences to make him happy, or no. For when he has once chosen it, and thereby it is become a part of his Happiness, it raises desire, and that proportionably gives him uneasiness, which determines his will, and sets him at work in pursuit of his choice on all occasions that offer. (\$56)

Clearly, Locke has changed his mind regarding freedom to will. But it is important to stress that his change of mind is not an acceptance of free 


\section{Dialogue}

will as he understands, and rejects, the notion. Let us clarify this by answering two questions. (1) What exactly is the "liberty in respect of willing" that appears in the fifth edition? (2) Why is it not free will ? What seems clear enough is that the kind of "liberty in respect of willing" that Locke has in mind in $\$ 56$ obtains only in the context of suspension and deliberation. So, presumably it can be understood in the following way. Suppose an agent has several desires and uneasinesses, one of which is an uneasiness that, being the strongest, would normally cause a volition (which we shall call "volition-1") to do A. On the one hand, if the agent does not suspend her desires in order to deliberate on whether to do A or not, then ceteris paribus the strongest uneasiness (along with a hasty last judgement) will produce volition-1 to do $A$. On the other hand, if the agent decides to suspend her desires in order to deliberate, she produces a volition (which we shall call "volition-3") that causes a suspension-deliberation process. If this occurs, then either (1) the result of her deliberation confirms as appropriate the initial desire cum uneasiness, in which case volition-1 to do A is produced after all, ${ }^{49}$ or (2) it disconfirms the initial desire and raises instead another desire cum uneasiness, which (together with a last judgement) produces a volition (which we shall call "volition-2") to refrain from doing $A$ (to do $B$ instead). Let us pursue the hypothesis under which the agent decides to deliberate. During the process of suspension and deliberation neither volition-1 nor volition- 2 is produced. Hence, as long as suspension and deliberation are under way, as regards the pair of alternatives volition- 1 and volition-2, it is not the case that, necessarily, either the one or the other is produced. Because of volition-3, the agent is able voluntarily "to forbear the act of volition"; it is not the case that "he must exert an act of his will, whereby the action proposed is made to exist, or not to exist." During the process, the unavoidability thesis does not apply to the pair of alternatives volition- 1 and volition-2. Because it does not apply, we have "liberty in respect of willing."

But what is this freedom? Let us first see what it is not. It cannot consist in an indifferency of the will, during suspension and deliberation, by which an agent could will to produce either volition- 1 or volition- 2 , since this is ruled out by the heteronomy principle ("no will determines itself, i.e., determines the acts of willing which belong to it"), an implicit premise of the argument of $\$ 25$ that Chappell correctly attributes to Locke. And one could not describe the situation during deliberation by saying that the agent is able either to will to do A (to produce volition-1) or to will to do B (to produce volition-2) as she wills, for that would suppose that one can will to will, and we have seen that Locke would object to that. Hence, the fact that the unavoidability thesis does not hold during suspension and deliberation does not imply-indeed, according to Locke, cannot implyan "Indifferency of [the will] on either side to act" in regard to volition-1 and volition- 2 . 
In order to have a volition one must be motivated to will the production of a specific action. The motivation is furnished by an uneasiness, the sort of action by a last judgement. ${ }^{50}$ During deliberation, that is, before an uneasiness is de-suspended and before a last judgement is made, one is not able to will, so it is pointless, Locke believes, to wonder whether one is free to will this or to will that, since one is not able to will at all. This is how we should read a letter of 1701 to van Limborch, in which Locke makes it clear that he would not accept an indifferency of the will by which a person could produce either volition- 1 or volition- 2 :

Moreover to argue as to whether a man, before the last judgement of the understanding, has liberty to determine himself to one or other of opposites seems to me to be arguing about nothing at all or about an impossibility. For who would ask, or what does it avail to ask, whether a man can determine himself to one or other of opposites when he is in a state in which he is unable to determine himself? For before the judgement of the understanding he is altogether unable to determine himself, and so it is idle to inquire whether in that state he has liberty to determine himself to one or other alternative when he is altogether unable to determine himself to either. ${ }^{51}$

I mentioned before that Locke does not say that free will is impossible merely because volitions are causally determined. What is implied by this passage, taken together with what we have previously seen, is that free will is impossible because of the kind of determination required for one to have a volition at all. If per impossibile a volition were not determined by an uneasiness and a last judgement, it would not be motivated and it would not be directed towards a certain sort of action, which is absurd given what a volition is.

For the foregoing reasons "liberty in respect of willing" is not free will as Locke understands, and rejects, the notion. (Another reason is that the mere expression "free will" contains the category mistake of ascribing one power, freedom, to another, the will.) But what, then, is it? It can only be the power to initiate a suspension-deliberation process or to refrain from doing so, as one wills. This is coherent with $\S 56$, and also with $\S 47$ quoted above. It also fits an important passage of another letter, of 1702, to van Limborch, where Locke says,

[Y]ou appear to doubt whether I hold that a man is free in Willing or in Understanding ...; you also ask whether the action of willing or understanding is free. To this question I answer thus:

1. Generally, indeed, that in my opinion a man is free in every action, as well of willing as of understanding, if he was able to have abstained from that action of willing or understanding; if not, not.

2. More particularly, as regards the will: there are some cases in which a man 
is unable not to will, and in all those acts of willing a man is not free because he is unable not to act. In the rest, where he was able to will or not to will, he is free. ${ }^{52}$

This may look like an endorsement of free will, but it is not. Let us focus on paragraph number two. Our foregoing discussion shows that there are two cases wherein "a man is unable not to will." One case is where, concerning an action "once proposed to [one's] thoughts, as presently to be done," the agent cannot avoid willing one way or the other (restricted unavoidability thesis). ${ }^{53}$ Another case is where suspension of desire is not possible, perhaps due to an overwhelming uneasiness demanding immediate action. As to the agent's being "able to will or not to will," this pertains to cases where the agent finds herself in a situation in which she can either suspend her desires, or not, in order to deliberate. Now, if she is able to suspend them she is able "not to will" for a certain period of time; that is, she can initiate a process whereby she brings it about that, during the process, she neither wills to do A nor wills to do $B$ (she produces neither volition-1 nor volition-2). And, if she is able to refrain from suspending her desires, she is "able to will"; that is, she is able to bring it about that she wills to A without deliberating (she produces volition-1). Now, it is important to note that one's being "able to will or not to will," so construed, is not free will as Locke understands it. It does not commit Locke to rejecting the heteronomy principle, nor to accepting volitions of volitions. In particular, the volition to initiate a suspension-deliberation process (volition-3) is not a volition that directly causes one to refrain from producing either volition-1 or volition- 2 ; it is a volition to bring about a process, knowing that the process, as long as it lasts, will temporarily make it causally impossible for oneself to produce either volition-1 or volition-2. And the volition to refrain from initiating a suspension-desire process is not a volition that directly causes volition-1; it is a volition to refrain from preventing some strong desire cum uneasiness to cause volition-1. In neither case does the agent will to will.

This is voluntary control of one's will, but the control is at a temporal and causal distance; it is only mediate, indirect. It is a voluntary control of what will causally determine one's will in the future. Chappell holds that the "liberty in respect of willing" of $\$ 56$ implies that Locke abandons what Chappell calls "volitional determinism." 54 This seems to be mistaken. Locke's "liberty in respect of willing" is compatible with the necessity (non-freedom) of all volitions, for it is compatible with the claim that no volitions are free because no volitions are performed voluntarily (in the sense discussed above concerning \$25). Furthermore, "liberty in respect of willing" is entirely compatible with causal determinism, for, to return to our preceding example, whichever of the two volitions (volition1 or volition-2) the agent eventually has, either one will be causally deter- 
mined. Locke's position only requires him to endorse the harmless point that different causal chains can lead to type-identical volitions (volition1 as produced after deliberation and volition- 1 as produced without deliberation, although type-identical, are not token-identical, since they would have different causes). And surely, too, the volition to initiate a suspension-deliberation process (volition-3) is itself causally determined, as would be the contrary volition if it occurred. The freedom in question is that of a person to initiate, or to refrain from initiating, a suspensiondeliberation process, as she wills. It is not that of a person to will to initiate the process, or to will to refrain from doing so. The latter would be inconsistent with Locke's rejection of free will.

This interpretation of the ability "to will or not to will" discussed in Locke's letter of 1702 to van Limborch fits in nicely, I believe, with $\$ 47$ and $\S 56$ quoted above. In $\$ 47$ the sort of freedom that Locke points to is that of thought and deliberation. We have seen that, for several reasons, Locke assimilates freedom to suspend one's desires with freedom to deliberate as two parts, or aspects, of a process. The assimilation continues in $\S 56$ and in the letter of 1702 to van Limborch. Because of this, the "liberty in respect of willing" of $\$ 56$ can be roughly identified with what Locke says, in $\$ 47$, is "improperly called free will," and with the ability "to will or not to will" of the letter. It is the limited freedom to initiate a suspensiondeliberation-process, or to refrain from doing so, as one wills. It is a power to act as one wills, not to will as one wills. Confirmation for this interpretation can be drawn from van Limborch himself, who understands Locke precisely this way:

You then deduce thence that the liberty of a man consists in this: that he can suspend the fulfilment of any of his desires and has complete liberty to consider them one after another, to examine their objects, to observe them from every side, and to compare them one with another, before he determines himself to acting. ${ }^{55}$

\section{Concluding Remarks}

Throughout II, 21 and his correspondence with van Limborch, Locke keeps a firm grasp on one, and only one, general conception of the power of freedom: the power to act as one wills. This conception applies (with due limitations) to bodily action, thought (deliberation), and suspension. Of course, volitions are acts, too. But, according to Locke, the same conception of freedom is inapplicable to acts of willing; one cannot will to will, and so one cannot will as one wills. His recognition of a "liberty in respect of willing," an ability "to will or not to will," is consistent both with causal determinism and with his denial of free will.

True, his three arguments against free will are hardly convincing. The category-mistake argument can be blocked by a friend of free will merely by 


\section{Dialogue}

rephrasing her position. The argument based on the unavoidability thesis is not universal in scope; it applies only to a certain class of actions. And the regressus argument is ad hominem; it can be resisted by the homo denying one of the premises attributed to him. Nevertheless, one can understand a deeper and more interesting motive for Locke's rejection of free will by keeping in mind that, for him, a volition not immediately caused by an uneasiness and a last judgement would be an absurdity: it would be unmotivated and it would not be directed towards a certain sort of act. This is what rules out the possibility of willing to will, and thus of willing as one wills, for if one could will to will, then one's volition would not be immediately caused by an uneasiness and a last judgement, but by a prior volition.

The successive alterations made by Locke from the second to the fifth edition of the Essay concerning uneasiness, suspension, and freedom in respect of willing are part and parcel of an evolving theory of freedom of thinking. All three are theoretically motivated by Locke's gradual recognition that freedom of thinking must be granted a more prominent role within his moral psychology than it was afforded in the first edition. And this, in turn, is motivated by Locke's recognition of the importance of weakness of the will. Yet, the three changes are not revolutions in Locke's position on human freedom taken as a whole. They are substantial adjustments made to accommodate an increasingly deeper and broader conception of what was present from the very outset, in the first edition: the free power of thinking. ${ }^{56}$

\section{Notes}

1 Textual alterations were made in the second (1694) and fourth (1700) editions, and prepared for the fifth (1706), which was to be posthumous. The single greatest textual revision concerns $\$ \S 28-38$ of the first edition, which were replaced by $\$ \$ 28-60$ in the second. Parts of the original eleven sections survived, however, and were variously relocated in the second edition.

2 Locke 1975, p. 11. Unless otherwise indicated, all future references to the Essay are to II, 21.

3 Cf. Chappell 1994, pp. 118-19. The recurrence of Chappell's name in this paper is a measure of what I owe his excellent essay.

4 Chappell locates Locke's assertion of what the former-not Locke-calls "volitional determinism" in $\$ 25$, and explains it in the following way: "Volitional determinism applies to concrete acts of willing, and it ascribes necessity de re to all of them. It says of every volition that it is a necessary action on the part of its agent" (Chappell 1994, p. 107; cf. p. 101). Chappell's explanation is not without its difficulties. The noun "necessity" seems to be used in a modal sense, whereas the adjective "necessary" seems to be used as Locke usually employs it in II, 21, namely, as a synonym for "non-free." Next, it is not clear whether or not Chappell thinks that, according to Locke, (p) volitions are necessary (non-free) actions because they are causally determined. Chappell does not 
attribute (p) to Locke in so many words. Yet, if this is not what he means, why does he call the position he does attribute to Locke in $\$ 25$ "volitional determinism"? True, he says that "no action is necessary for Locke simply by being the effect of antecedent causes" (p. 104), but the context does not indicate that Chappell here includes volitions among actions. Therefore, in doubt as to whether Chappell attributes (p) to Locke or not, I will give independent reasons for two distinct claims: (1) for the claim that Locke's late acceptance of "Liberty in respect of willing" does not contradict, and does not lead him to abandon, the thesis that all volitions are non-free (that is, the thesis that free will is impossible); and (2) for the claim that his acceptance of "Liberty in respect of willing" does not contradict, and does not lead him to abandon, the thesis that all volitions are causally determined. If Chappell does not attribute (p) to Locke, then my argument in favour of claim (2) is no objection against him.

5 Cf. Locke 1975, II, 27, $\$ \$ 9$ and 26.

$6 \mathrm{Cf}$, for example, II, 21, $\$ 6$ and 16-20.

7 "For ... there being but two sorts of Action, whereof we have any Idea, viz. Thinking and Motion . . ." (\$4); "All the Actions that we have any Idea of, reducing themselves, as has been said, to these two, viz. Thinking and Motion ..." $(\S 8)$.

8 II, $21, \$ 5$. I agree with Lowe that in Locke an action (a bodily movement or a thought) is voluntary if, and only if, it is directly caused by a volition (cf. Lowe 1986). Lowe's reading has been criticized by Yaffe (cf. Yaffe 2000, pp. 104ff.). Although Yaffe agrees that causation by a volition is necessary for an action to be voluntary, he does not think that Locke holds that it is sufficient. Instead, Yaffe proposes the following: "A proper action $A$ of an agent $S$ is voluntary if and only if it satisfies a volition to do A on the part of S" (p. 109), keeping in mind that "it is a necessary condition of a volition's satisfaction that it causes the action that it is aimed at" (p. 110). A proper discussion of Yaffe's appealing position would exceed the space I have. Let me make only two points. Firstly, Locke's sentence ("The forbearance or performance of that action, consequent to such order or command of the mind is called Voluntary") should be taken within its context at face value. It means that "the forbearance or performance" of an action is called "voluntary" when it is caused by "such order or command." And why should it be called "voluntary" when it is caused by a volition, unless being so caused is a sufficient condition for its being voluntary? Secondly, in my view Yaffe's interesting defence, theoretical argument cum textual evidence, of his interpretation does not support the claim that Locke held the position he ascribes to him. It lends support to the claim that, if Locke had discussed with present-day philosophers of action, and been led by them to think seriously about deviant causal chains and conditions of satisfaction of intentional states, he might have accepted Yaffe's suggestion.

9 According to Webster's New Universal Unabridged Dictionary, 1992 (p. 499), "endeavo[u]r" and "attempt" are synonyms of "exertion."

10 Locke 1982, p. 327. 
11 Locke does not explicitly distinguish between involuntary and non-voluntary actions. He seems to classify both under the heading "involuntary," as when he says that "whatsoever action is performed without such a thought of the mind [a volition] is called Involuntary" (II, 21, §5).

12 Cf. Chappell 1994, p. 104. On Locke as a compatibilist, cf. Yaffe 2000, n.5.

13 "Liberty is for me the power of a man to act or not to act, according to his will: that is to say, if a man is able to do this if he wills to do it, and on the other hand to abstain from doing this when he wills to abstain from doing it: in that case a man is free" (Locke 1982, p. 406, my italics).

14 "For wherever restraint comes to check that Power, or compulsion takes away that Indifferency of Ability on either side to act, or to forbear acting, there liberty, and our Notion of it, presently ceases" $(\$ 10)$; "This [Necessity] in an Agent capable of Volition, when the beginning or continuation of any Action is contrary to that preference of his Mind, is called Compulsion; when the hind'ring or stopping any Action is contrary to his Volition, it is called Restraint" (\$13).

15 Cf. $\$ \$ 8-11$.

$16 \mathrm{Cf}$. the example Locke discusses in $\$ 71$.

17 Cf. Locke 1982, p. 407, and Locke 1975, II, 21, §71.

18 Locke 1982, p. 681. "For the most part a man is able not to open his eyes or not to turn his gaze to this or that object, but when his eyes are opened and turned to the sun or moon he necessarily sees the brightness and the shape that present themselves to his observation. What I have said of the eyes may be transferred to the understanding: the principle is the same for both" (p. 681). Cf. IV, 20, §16.

19 Locke 1982, pp. 680-681.

20 II, 14, §15; cf. II, 7 §3.

21 Locke 1982, p. 411: "every single volition is always preceded by some judgement of the understanding about the thing to be done, and . . . that judgement that immediately precedes the volition or act of willing is in that case the last judgement of the understanding."

22 "I think, a Man, who has weighed them [proofs] can scarce refuse his Assent to the side, on which the greater Probability appears" (IV, 20, $\$ 15$ ); "it is not in our Choice, to take which side we please, if manifest odds appear on either. The greater Probability, I think, in that Case, will determine the Assent: and a Man can no more avoid assenting, or taking it to be true, where he perceives the greater Probability, than he can avoid knowing it to be true, where he perceives the Agreement or Disagreement of any two Ideas" (IV, 20, §16).

23 Cf. n.21 above.

24 I thank an anonymous referee for help with this point.

25 All of the preceding quotations are from Locke 1982, pp. 410-11. Much of the same doctrine is to be found in the Essay, II, 21, although not stated as explicitly as in the letter quoted above. In $\$ 47$ Locke speaks of "the last result of a fair Examination," which can only be the last judgement of deliberation. In $\S 48$ 
he speaks of the "last judgment of the Good or Evil, that is thought to attend its Choice," and makes clear a few lines further that the judgement concerns action: "the last result of our own Minds, judging of the good or evil of any action." And in $\$ 52$ he says that "the last determination of the Judgment" can be either "upon an hasty and precipitate view, or upon a due and mature Examination."

26 Essay, first-edition text at bottom of pp. 253-54.

27 Locke 1975 , II, 21, \$33. Bennett rightly notes that Locke is uncertain whether uneasiness is identical with desire, is a cause of desire, or is an effect of desire; Locke vacillates between the three possibilities (cf. Bennett 1994, pp. 96-97), so let us say merely that an uneasiness is always closely connected to a desire inasmuch as there is no desire without some uneasiness, however faint.

28 As testifies the sentence by which, in the second edition, Locke replaces the quotation before last (cf. n.26 above): "'tis as much a perfection, that desire or the power of Preferring should be determined by Good, as that the power of Acting should be determined by the Will, and the certainer such determination is, the greater the perfection" $(\$ 48)$.

29 That Locke takes the cases he discusses in $\$ 35$ to be cases of weakness of the will appears from his quoting Ovid: Video meliora proboque, Deteriora sequor.

30 As appears in the following sentence, for example: "The Idea of it [an absent good] indeed may be in the mind, and view'd as present there: but nothing will be in the mind as a present good, able to counter-balance the removal of any uneasiness, which we are under, till it raises our desire, and the uneasiness of that has the prevalency in determining the will. Till then the Idea in the mind of whatever good, is there only like other Ideas, the object of bare unactive speculation; but operates not on the will, not sets us on work . .." (\$37).

31 I am somewhat simplifying matters by leaving out of the picture two other factors that Locke considers: the time that it would take to attain the proposed goods, and the probability of success.

32 For example, the reason for which we do not constantly endeavour to work towards attaining the "Joys of Heaven," Locke explains, is that we seldom consider such joys relevant to our desire for happiness; thus, the idea of such an absent good produces little or no uneasiness (cf. $\$ \$ 38$ and 44 ).

33 Locke 1982, pp. 410-11.

34 Cf., for example, $\$ 40$.

35 Yaffe handles $\$ 47$ in a way I fail to understand. He says: "the passage just quoted seems to be [but, according to Yaffe, is not really] an explicit statement that an agent who has the power to suspend the effect of uneasiness in the determination of the will and who (thereby) has the power to deliberate ... has (what is mistakenly called) freedom of will"' (cf. Yaffe 2000, p. 52; cf. p. 19). On the contrary, Locke should be taken at face value and as meaning what he says. I therefore disagree with Yaffe's further claim that what Locke says is improperly called freedom of will is to be identified with the following condition: "either [an agent's] volitions are determined by the good, or she has the 
power to bring it about that her volitions are determined by the good" ( 2000 , p. 54; cf. pp. 59-61). What Locke says, in $\$ 47$, is improperly called free will is obviously the power to suspend one's desires. (I also find Yaffe's reading of $\$ 22$ strained, his efforts to convince notwithstanding [cf. 2000, pp. 27, 144-45]).

36 Cf. Ayers 1991, Vol. 2, p. 194.

37 In $\$ 50$ Locke defines "standing still, where we are not sufficiently assured of the way" as "to suspend any particular desire, and keep it from determining the will, and engaging us in action."

38 "I desire it may be well consider'd, whether the great inlet, and exercise of all the liberty Men have, are capable of, or can be useful to them, and that whereon depends the turn of their actions, does not lie in this, that they can suspend their desires, and stop them from determining their wills to any action, till they have duly and fairly examin'd the good and evil of it, as far forth as the weight of the thing requires" (\$52).

39 We are "obliged to suspend the satisfaction of our desire in particular cases" (§51). It is a "duty" of agents to "suspend their desires, and stop them from determining their wills to any action, till they have duly and fairly examin'd the good and evil of it" (\$52).

40 Ayers 1991, Vol. 2, p. 194.

41 Cf. Chappell 1994, pp. 104-10.

42 Chappell 1994, p. 107.

43 Cf. Chappell 1994, pp. 106-107.

44 Rickless (2000) believes that Locke doubly restricts the scope of his argument in \$23: he restricts it to actions "that are to be considered only at the time they are to be performed," and exclusively to actions that are "stoppings of processes" (p. 50). According to Rickless, Locke's conclusion is: "A man considering presently stopping a process in which he is presently engaged is not free in respect of the act of willing" (ibid., p. 52). I accept, of course, Rickless's first restriction, since we have seen that Locke virtually says as much. But there are three reasons for which I find it difficult to accept Rickless's second, more drastic, restriction, that excludes actions that are, for instance, beginnings of processes. Firstly, the textual evidence brought forth by Rickless seems insufficient: surely the mere fact that Locke illustrates the point made in $\$ 23$ by the example, in $\$ 24$, of "a Man that is walking, to whom it is proposed to give off walking" is no sure sign that Locke believes, without saying so, that the argument of $\$ 23$ does not apply just as well to beginnings as to stoppings of processes, and to other modes of acting. Secondly, according to Rickless, Locke makes the second restriction in the second edition of the Essay (1694); however, in a letter of 1701 to van Limborch Locke reiterates the point made in $\$ 23$ in very general terms, without even alluding to stoppings of processes: "when any action has been proposed to a man, he cannot abstain from Volition; he must necessarily Will either that proposed action or abstention from it" (Locke 1982, p. 410, my italics). Thirdly, Rickless's second restriction appears to be needless if Locke's position in $\$ 23$ can be correctly described as I have attempted to do above. 
45 Cf. Chappell 1994, pp. 107-10. Rickless proposes a very different reconstruction of Locke's argument in $\$ 25$ (cf. Rickless 2000 , pp. 56-65). I find Chappell's reconstruction preferable to Rickless's because I agree with Chappell (and with Yaffe 2000, p. 29) that Locke's argument is against freedom to will, whereas Rickless thinks that "Section 25 contains an argument to the conclusion that human beings are free with respect to their volitions ..." (Rickless 2000 , p. 65). Textual reasons against this reading are given in $\mathbf{n} .48$ below.

46 Cf. Chappell 1994, pp. 111-12.

47 Rickless attributes to Locke the view that: "[human beings'] acts of willing to perform volitions are not distinct from those volitions" $(2000$, p. 65). This is close to my interpretation, but I am not sure we are saying the same thing, because Rickless seems to say that there are willings to perform volitions, only that they are not distinct from the latter.

48 II, 21, §25. I agree with Chappell that "the absurdity lies . . . in an affirmative answer to [the question]" (Chappell 1994, p. 108). In other words, Locke intends us to see that the reply is obviously negative. This has been contested by Rickless, who holds that "what makes [the] question absurd is precisely that an [affirmative] answer to it is .. . obviously true" (Rickless 2000, p. 64; cf. p. 63). Rickless is mistaken, for the lines quoted above from $\$ 25$ are immediately preceded by the following: "Since then it is plain, that in most cases a Man is not at liberty, whether he Will, or no; the next thing demanded is, Whether a Man be at liberty to will which of the two he pleases, Motion or Rest. This Question carries the absurdity of it so manifestly in it self, that one might thereby sufficiently be convinced, that Liberty concerns not the Will" (\$25). If, as Rickless correctly says, it is the obviousness of the answer that makes the question absurd (to ask), and if, as Locke says, the absurdity is such that "one might thereby sufficiently be convinced, that Liberty concerns not the Will," then the obvious answer is negative. In the second place, pace Rickless (cf. 2000, p. 64), Locke cannot be saying that it is obvious that "a man can will, what he wills" in the sense that whatever is actual is possible, for that reading is hardly compatible with what he says next: "A Question, which, I think, needs no answer: and they who make a Question of it, must suppose one Will to determine the Acts of another, and another to determinate that; and so on in infinitum" (\$25). Indeed, it does not follow from (1) one's doubting that whatever is actual is possible (as if one could doubt that!) that (2) one "must suppose one Will to determine the Acts of another," etc. The two points are unrelated.

49 Volition-1 as produced without deliberation is type-identical, but not tokenidentical, to volition-1 as produced after deliberation, for the two volitions would not have the same causes.

50 This is why Locke ridicules "an antecedent indifferency, as [his opponents] call it": "For it is pretty hard to state it . . . immediately after the Judgment of the Understanding, and before the determination of the Will, because the determination of the Will immediately follows the Judgment of the Understanding." The passage continues: "and to place Liberty in an indifferency, antecedent to 


\section{Dialogue}

the Thought and Judgment of the Understanding, seems to me to place Liberty in a state of darkness, wherein we can neither see nor say any thing of it; at least it places it in a subject incapable of it, no Agent being allowed capable of Liberty, but in consequence of Thought and Judgment" (\$71).

51 Locke 1982, pp. 328-29, my italics.

52 Locke 1982, p. 680.

53 Chappell (1994, p. 118) takes Locke, in this letter, to abandon the unavoidability thesis. But if the thesis is restricted in the way I have tried to show, then there is no reason to believe that Locke abandons it here or, as far as I can see, elsewhere.

54 Cf. Chappell 1994, p. 118.

55 Locke 1982, pp. 275-76. However, contrary to what van Limborch says, Locke does not speak of "complete liberty" in this respect. Such freedom, we have seen, is limited.

56 I thank an anonymous referee for comments on an earlier version of this article.

\section{References}

Ayers, $M$.

1991 Locke. 2 vols. London: Routledge.

Bennett, J.

1994 "Locke's Philosophy of Mind." In The Cambridge Companion to Locke. Edited by V. Chappell. Cambridge: Cambridge University Press, pp. 89-114.

Chappell, V.

1994 "Locke on the Freedom of the Will." In Locke's Philosophy: Content and Context. Edited by G. A. J. Rogers. Oxford: Clarendon Press, pp. 101-21.

Locke, J.

1975 An Essay Concerning Human Understanding. Edited by P. H. Nidditch. Oxford: Clarendon Press.

1982 The Correspondence of John Locke. Vol. 7. Edited by E. S. de Beer. Oxford: Clarendon Press.

Lowe, E. J.

1986 "Necessity and the Will in Locke's Theory of Action." History of Philosophy Quarterly, 3, 2: 149-63.

Rickless, S. C.

2000 "Locke on the Freedom to Will." The Locke Newsletter, 31: 43-67.

Webster's New Universal Unabridged Dictionary

1992 New York: Barnes \& Noble Books.

Yaffe, $G$.

2000 Liberty Worth the Name: Locke on Free Agency. Princeton, NJ: Princeton University Press. 